\title{
O USO DO YOUTUBE COMO FERRAMENTA DE MARKETING: ESTUDO DE CASO DA IMOBILIÁRIA TECNISA
}

\section{Carine Lopes Lourenço Werneck}

\author{
Eduardo Picanço Cruz
}

\begin{abstract}
RESUMO
0 presente estudo busca analisar a eficiência do site Youtube como estratégia promocional e publicitária na internet por parte das imobiliárias. A primeira parte do trabalho consiste no embasamento teórico necessário para o estudo, com a apresentação dos conceitos básicos de marketing, abordando sua história, e os conceitos do composto de marketing, enfatizando promoção. Segue também um estudo de mídia, e de um dos principais meios de comunicação de massa que é a internet. São abordados em seguida os conceitos de Youtube, e como este está sendo usado pelo mercado imobiliário. Por fim, foi analisado o caso da Imobiliária Tecnisa, uma empresa que aposta no uso inteligente do mix de canais de comunicação existentes na web, seguindo a tendência do mercado atual. Pôde-se concluir a importância do Youtube para este mercado a partir das respostas dadas pela empresa a respeito de suas estratégias no uso do website.
\end{abstract}

Palavras-chave: Marketing. Internet. Youtube. Empresas imobiliárias. Tecnisa.

\begin{abstract}
The present study seeks to analyze the efficiency of the Youtube website like promotional and publicity internet strategy to the real estate companies. The first part of this work is a theoretical base necessary for the study, with the presentation of the basic concepts of marketing, addressing its history, and the marketing mix concepts, emphasizing promotion. Also follows a study of media, and a major means of mass communication that is the internet. Are addressed then the concepts of Youtube, and about how it is using by the real estate market. Finally, it examined the case of property real estate Tecnisa, a company that advocates the intelligent using of mix of communication channels in the web, following the market trend. It was observed the importance of the Youtube for this market from the answers given by the company about their strategies in the use of the website.
\end{abstract}

Keywords: Marketing. Internet. YouTube. Real estate companies. Tecnisa. 


\section{INTRODUÇÃO}

Em um ambiente empresarial competitivo e com a evolução da tecnologia, surge a necessidade das empresas de se diferenciarem, ampliarem seus mercados e atingirem públicos novos. Considerando esse cenário, as empresas começaram a enxergar na internet uma importante ferramenta para ampliar as oportunidades de negócios. Embora ainda existam algumas empresas com uma visão conservadora, a publicidade online cresce a cada ano no Brasil, mas para alcançar seus clientes atuais e potenciais é grande a necessidade e a importância que uma empresa precisa dar ao posicionamento do site na internet.

Com um consumidor mais moderno, com novas expectativas, e integrado tanto no mundo real quanto no virtual, as ações estratégicas das empresas para o uso da internet buscam eficiência e resultados quase que imediatos, para não perder de vista o consumidor.

Até os locais de compra convencionais estão ameaçados pelos sites de compra via internet. Nos países desenvolvidos, a maioria dos consumidores utiliza a rede mundial para tomar a decisão de compra de um produto ou serviço. Esse hábito ainda está em evolução no Brasil, mas a tendência é que cresça ainda mais.

A revolução digital mudou os conceitos de espaço, de tempo, e de massa. Uma empresa já não precisa ocupar muito espaço físico, ela pode ser virtual, estar em qualquer parte e alcançar os seus clientes onde eles estiverem. Essa evolução proporcionou mudanças importantes, como por exemplo, o envio e recebimento de mensagens instantâneas, e músicas e filmes podem ser enviados de forma fácil e rápida pela web.

Através das comunicações estabelecidas com auxílio de ferramentas de marketing digital, os profissionais de mercado estão possibilitados a atingir níveis de interação com seus clientes baseados em relações cada vez mais cômodas e convenientes para seus clientes, permitindo um contato amplo, a qualquer hora do dia e onde quer que os clientes estejam.

Essa pesquisa se propõe a responder aos seguintes questionamentos: Como o Youtube está sendo utilizado pelas imobiliárias? Quais os benefícios de disponibilizar vídeos de imóveis a venda ou para aluguel neste website?

\section{MARKETING}

Segundo a American Marketing Association (A.M.A.) (2004), o marketing vai além das relações de troca, ele envolve a criação, a comunicação e a entrega de valor para os clientes, buscando administrar relacionamentos com eles, ou seja, além da troca em si o foco está na manutenção de relacionamentos duradouros (DARROCH et al., 2004). Além disso, este conceito explicita a necessidade da organização de lidar com diversos públicos de interesse, como fornecedores, vendedores, órgãos do governo e funcionários, e clientes.

Para Robert Hass (1978), o marketing é um o processo de descoberta e interpretação das necessidades e desejos do consumidor para as especificações de produtos e serviços, e a criação e respectiva expansão da demanda para esses.

O British Chartered Institute of Marketing (Middleton, 2002) define marketing como "o processo de gerenciamento responsável por identificar, antecipar e satisfazer às exigências dos clientes, de forma lucrativa, a fim de atender aos objetivos organizacionais". Segundo esse 
conceito, o marketing é o processo administrativo de identificação e satisfação das necessidades dos consumidores, de maneira a satisfazer também os objetivos das organizações.

Seguindo essa linha, Churchill (2000, p. 4) afirma: "marketing é o processo de planejar a concepção, o preço, a promoção e a distribuição de bens e serviços para criar trocas que satisfaçam aos objetivos individuais e organizacionais".

De acordo com Philip Kotler e Gary Armstrong (2003), os dois principais objetivos do Marketing são atrair novos clientes, sempre prometendo algo de valor, seja um desconto, brinde ou serviço diferenciado; e manter os clientes atuais através da satisfação de suas necessidades.Em seu livro "Marketing de A a Z", Kotler (2003) define o marketing como:

Uma função empresarial que identifica necessidades e desejos insatisfeitos, define e mede sua magnitude e seu potencial de rentabilidade, especifica que mercados-alvo serão mais bem atendidos pela empresa, decide sobre produtos, serviços e programas adequados para servir a esses mercados selecionados e convoca a todos na organização para pensar no cliente e atender ao cliente.

No entanto, o conceito de Marketing pode ser mal compreendido. Muitas pessoas associam o marketing à "enganação", acham que é uma forma de fazer com que pessoas comprem o que não precisam com o dinheiro que elas não têm. Ou acham que Marketing significa apenas tomar decisões para satisfazer os desejos dos Clientes ou criar esses desejos neles, para vender os produtos de qualquer maneira, mesmo que as pessoas não o queiram. Na verdade, Marketing é um estudo baseado em diversas ciências (Sociologia, Psicologia, Matemática, Antropologia, Estatística, Filosofia, dentre outras).

A tradução de marketing para o português é mercadologia, muito embora os dicionários já disponibilizem o vocábulo marketing. A tradução com a terminação "logia", reforça a idéia de que corresponde a um campo de estudos. 0 Marketing enquanto ciência tem o objetivo de conhecer o comportamento de pessoas e, a partir disso, tomar ações sobre elas, para satisfazer necessidades e desejos de cada um.

Marketing também não é sinônimo nem necessariamente parte da administração. As

diretrizes administrativas de uma empresa podem e deveriam ser diretrizes de marketing. Isto é: Uma administração estratégica voltada para o cliente e as demandas de mercado. Marketing também não é sinônimo de vendas ou vendedor. Mesmo porque o ideal de um planejamento de marketing é criar um produto que venda por si mesmo. Reduzindo assim a necessidade de gastos excessivos com uma grande equipe de vendas.

\section{COMPOSTO DE MARKETING}

Para Kotler e Keller (2006), uma administração de marketing bem sucedida envolve o processo de criar, entregar e comunicar valor para os clientes. Toda estratégia de marketing necessita definir basicamente quatro variáveis, conhecidas como composto ou mix de marketing.

Trata-se do conjunto de pontos de interesse para os quais as organizações devem estar atentas se desejam perseguir seus objetivos de marketing. Através do composto de marketing, as empresas procuram administrar suas estratégias e táticas para que a resposta do consumidor seja a esperada por eles (KOTLER E ARMSTRONG, 2003). 0 composto é dividido 
em quatro áreas primárias do processo decisório associado ao marketing, conhecidas como os "4 P's": Produto, Preço, Praça (ou Ponto de venda), e Promoção (Comunicação). Proposto por E. Jerome McCarthy em 1960, o modelo dos 4 P's expressa o seguinte raciocínio: As empresas produzem um determinado produto, este é alvo de uma promoção, que tem por objetivo comunicar, informar o consumidor sua disponibilidade em uma dada praça (ponto de venda, distribuição), a um determinado preço. (CHURCHILL E PETER, 2000)

Toda organização deve desenvolver um mix de marketing. Juntos, esses quatro fatores devem satisfazer às necessidades de mercados-alvo e, ao mesmo tempo, atingir os objetivos de marketing da organização.

Segundo KOTLER E ARMISTRONG (2003), O composto de marketing é "um conjunto de ferramentas de marketing táticas e controláveis que a empresa utiliza para produzir a resposta que deseja no mercado-alvo." CHURCHILL E GILBERT (2000) questionam os quatro P's pelo o fato de que a maneira como o vendedor vê o produto pode não ser a mesma do comprador e para esta questão pode-se implantar os quatro C's : Cliente (tudo que se refere ao produto em si, como características),

Custo (políticas de preço, desconto formas de pagamento), Conveniência (tarefas necessárias para apresentar o produto ao consumidor da melhor forma) e Comunicação (tarefas de comunicação que visam promover o consumo do produto ou serviço, promoção de vendas, publicidade, força de vendas, marketing direto, etc.).

\section{PROMOÇÃO (COMUNICAÇÃO)}

O "P" Promoção é definido por LAS CASAS (1997) como "variável controlável do composto mercadológico com significado de comunicação". Para ele, a intenção é usar formas eficientes para informar aos consumidores a respeito dos seus produtos, serviços ou a formação própria da imagem da empresa. A comunicação de marketing cuida do relacionamento da empresa ou empreendimento com o segmento mais importante da esfera de competitividade: o cliente, o consumidor, o usuário.

É a propaganda que vai levar ao conhecimento do consumidor todo o trabalho feito nos três "Ps" anteriores e ajudará também a convencer o cliente na hora da compra, além de fortalecer a imagem do produto/empresa e buscar fidelidade ou preferência.

Nickels e Wood (1999) fomentam que a comunicação (promoção) não se limita a simplesmente informar o mercado acerca de um produto/serviço, o que se pretende é desenvolver uma comunicação a fim de levar o consumidor à realmente adquirir o produto, satisfazendo a sua necessidade, e maximizando o lucro da empresa. "O objetivo da comunicação integrada de marketing é manter um diálogo com os clientes e outros grupos de interesse, permitindo que a empresa responda de forma rápida às suas necessidades e desejos em constante mutação" (NICKLES E WOOD, 1999). E lembra também que a comunicação deve envolver relacionamentos longos e duradouros não só com clientes mas com os parceiros do canal, empregados e outros grupos de interesse.

Para o desenvolvimento de uma estratégia promocional, os objetivos de marketing devem ser usados. 0 mix promoção consiste no desenvolvimento de algumas atividades promocionais, tais como propaganda, relações públicas, publicidade, venda pessoal, promoção de vendas, marketing direto e merchandising. 


\section{PROPAGANDA}

A Propaganda é a mais conhecida de todas as ferramentas do marketing dentro do "P" promoção. Comumente confundida com marketing a propaganda tem por objetivo atingir um grande número de pessoas e apresentar-se repetitivamente, a fim de fixar a mensagem na mente do consumidor.

SCHEWE (1982) define propaganda como "forma impessoal de comunicação, paga por um patrocinador identificado e é transmitida por mídia de massa”. Há vários meios de divulgar um produto, pode-se citar como mídia de massa: jornais, revistas, televisão, radio, outdoor, internet e etc, mas há sempre um que será mais eficiente e conveniente para a divulgação, para isso é necessário uma delicada análise.

Ao contrário da publicidade, a propaganda é paga, e, portanto tem necessariamente que dar retorno à empresa, em forma de incremento nas vendas. Neste aspecto é importante que a empresa selecione a mídia correta, a fim de fazer com que a propaganda seja eficaz. LAS CASAS (1997) salienta que é através da propaganda que as empresas podem manter cooperação de seus intermediários, para familiarizar seus consumidores com o uso dos seus produtos, criar e manter uma imagem de credibilidade, lançar novos produtos, estimular demanda, entre outros propósitos.

Os anunciantes devem estabelecer objetivos claros que determinem se a propaganda deve informar, persuadir ou relembrar aos compradores. (KOTLER E ARMISTRONG, 2003). Esses objetivos devem basear-se em decisões anteriores sobre o mercado-alvo, posicionamento e mix de marketing. 0 objetivo de propaganda é uma tarefa específica de comunicação a ser realizada para um público-alvo específico durante um determinado período. Com um produto bom, que atenda as exigências de um segmento, a empresa poderá ter suas vendas aceleradas com a utilização dessa importante ferramenta mercadológica. (LAS CASAS, 1997).

\section{PUBLICIDADE}

A publicidade é uma atividade que quase sempre está incluída na função de relações públicas. (SCHEWE, 1982). As Relações Públicas têm a função de criar percepções na mente dos consumidores, e a publicidade tem a capacidade de defender e manter viva essa percepção. É o ato de tornar público uma idéia.

Diferencia-se da propaganda por não ter custo para a empresa. Ou seja, o fator diferenciador entre a propaganda e a publicidade, é que esta última não é paga e nem controlada pela empresa, exige da empresa pouco esforço para divulgação. "São estímulos não pessoais para criar a demanda de um produto ou unidade de negócio através dos meios de comunicação como rádio, TV e outros veículos teoricamente com materiais não pagos pelo patrocinador". (Cobra, 2000)

Publicidade é a estratégia de informação que explora o caráter informativo da comunicação, criando fatos, provocando notícias, desenvolvendo a formação da imagem da organização, serviço, indivíduo ou marca. Não possui objetivos comerciais.

\section{MÍDIA}

Segundo LAS CASAS (1997), a palavra mídia é o veículo, ou meio designado para a transmissão e divulgação da mensagem. 
Para Kotler e Armstrong (2003), mídia pode ser entendida como canais de comunicação impessoal, estas incluem a mídia impressa - jornais, revistas, mala direta; a mídia eletrônica rádio, televisão; e a mídia de display - outdoors, cartazes e pôsteres. Sant'Anna (1998) classifica mídia da seguinte forma: veículos visuais - para serem lidos ou vistos, como jornais, revistas, cartazes, painéis e luminosos; veículos auditivos - rádio e altofalantes; veículos audiovisuais - para serem ouvidos e vistos como televisão e cinema, e veículos funcionais para desempenhar uma dada função como amostras, brindes e concursos.

Cobra ainda complementa com alguns elementos que devem ser considerados na escolha da mídia: hábitos de mídia do público-alvo, as características do produto, os custos da mídia, objetivos da mensagem, audiência do veículo, circulação do veículo e audiência efetiva (número de pessoas com as características do público-alvo, que estavam expostas ao veículo).

LAS CASAS (1997) ressalta que "ao determinar o veículo mais adequado para a estratégia de marketing da companhia, devem ser considerados outros aspectos como circulação, audiência dos veículos eletrônicos, público que atinge, volume de audiência e freqüênciadesejada para se atingir ao consumidor."

Uma mensagem usada em uma mídia, sempre tem o intuito de transmitir uma idéia ou informação que cause uma reação preestabelecida no público-alvo. Aplicada à propaganda, o objetivo torna-se divulgar uma marca, produto ou serviço visando evidenciar seus benefícios, tanto os tangíveis quanto os intangíveis.

As mídias se multiplicam a cada ano e geram dúvidas no empresário, que quer saber qual delas está sendo a mais vista, qual dará melhor resultado para a divulgação do seu produto.

Portanto é preciso reduzir as possibilidades de erro na escolha do veículo mais adequado. Dentre os diversos meios de mídia, pode-se citar a revista, o rádio, a televisão, o outdoor, o indoor, o busdoor, a mala direta, o tablóide de ofertas, a revista de produtos e preços, o catálogo, o encarte, a internet, os painéis, etc. Para este trabalho, será abordada a mídia internet como principal veículo de divulgação.

\section{INTERNET}

A palavra Internet significa internetwork system (sistema de interconexão de rede de comunicação). É um sistema de redes de computadores interconectadas de proporções mundiais, reunindo milhões de computadores (DIZARD, 2000) e milhões de usuários, permitindo o acesso a informações e todo tipo de transferência de dados.

A Internet é o mais importante meio de difusão desde a invenção da imprensa. Substitui tudo o que havia antes e é, da maneira mais radical, promotora da transformação. Quando qualquer um pode ser escritor, no sentido mais amplo e para um público global, muitos de nós tentaremos sê-lo. A Net está a desmentir tantas das coisas que dizíamos acerca das mídias e dos modelos empresariais que mal conseguimos acompanhar as transformações; é difícil manter o equilíbrio quando está em curso a passagem de um hierarquia vertical para algo de muito mais democrático e, é certo, confuso. (GILLMOR, 2005, P. 227) ROSA (1998) ressalta que a internet é um sistema que permite a interconexão de diferentes redes de computadores, possibilitando o acesso a um banco de dados global, além de permitir a comunicação entre empresas e usuários do mundo inteiro.

Internet, como rede mundial de computadores interconectados, é um privilégio da vida moderna para o homem moderno. É o maior repositório de informações acessíveis a qualquer 
pessoa que a acesse de qualquer parte do mundo. E o que torna a Internet tão diferente das outras invenções humanas é o insignificante período de tempo em que ela precisou para ser usada por milhões de pessoas, diferente de outras mídias como a televisão e o rádio, que levaram muito mais tempo para se massificar. Permite ainda interligar sistemas informáticos de todo o mundo, possibilitando a comunicação e a troca de informação de uma forma fácil e rápida. Os meios para efetuar essas ligações são distintos, e incluem rádio, linhas telefônicas, linhas digitais, satélite, ISDN, fibra-óptica, etc.

Os serviços disponíveis na Internet são diversos, permitindo que os computadores conectados possam ser usados, entre outras coisas, para enviar emails (mensagens eletrônicas), transferência de arquivos e acesso à informação na rede (world wide web). Contém uma vasta variedade de informações e assuntos.

O número de usuários da internet e quantidade total das informações disponíveis nessa rede mundial cresce a cada ano, e o que fez com que esta se tornasse a mídia de massa mais importante desde a televisão. Por envolver computadores e utilizar dados digitalizados, permite ao usuário uma maior liberdade na criação de informações e na maneira que vão consumi-las, por isso é mais interativa do que a televisão, o rádio e o jornal, que limitam a interação do usuário à seleção do conteúdo.

\section{MARKETING NA INTERNET}

Este novo contexto social e empresarial proporcionado pelo avanço tecnológico e da internet, encerra em si novas regras nas relações entre empresa e cliente, formando clientes cada vez mais exigentes e conhecedores, o que implica uma necessidade de reflexão sobre as mudanças que esta nova realidade origina, ao nível de Marketing. VASSOS (1998) salienta que a internet não é um meio de vendas, é um meio de comunicação, educação e suporte. A partir destes princípios, ele propõe que a empresa deve moldar seus esforços de marketing de acordo com esse meio e aumentar suas chances de sucesso.

Um dos fatores que contribui muito para o crescimento de investimentos realizados na internet são as formas de medir os resultados. Com sistemas de cadastros de usuários e relatórios on-line fica mais fácil para o proprietário do site informar ao patrocinador dados relevantes para definir a estratégia de marketing a serem adotadas.

Muitas empresas acreditam que o objetivo do marketing é apenas aumentar as vendas, mas para VASSOS (1998), o objetivo é aumentar os lucros, assim ele cita três objetivos que a empresa deve enfocar para um plano completo de marketing:

_ Aumentar as vendas;

_ Diminuir o custo de se fazer negócios;

_ Ampliar a comunicação com todas as audiências, para alcançar os objetivos anteriores.

A natureza de auto-atendimento dos sites favorece uma economia de custos sem precedentes. À medida que os consumidores começam a utilizar a Internet, as empresas podem atendê-los sem altos custos de distribuição, oferecendo um meio rápido e relativamente barato de coleta e transferência de informações.

\section{YOUTUBE}

A palavra "youtube" foi feita a partir de dois termos da língua inglesa: "you", que significa 
"você" e "tube", que provêm de uma gíria que se aproxima muito da palavra "televisão". Em outras palavras, pode-se entender como "televisão feita por você". Essa é justamente a sua principal função, é um website que permite que os seus usuários carreguem, assistam e compartilhem vídeos em formato digital.

Fundado em fevereiro de 2005, em uma garagem em São Francisco (Califórnia, EUA) pelos jovens Chad Hurley e Steve Chen, o Youtube foi criado com o objetivo de compartilhar vídeos com os amigos, já que estes eram muito grandes, o que dificultava seu envio por e-mail.

Os dois eram funcionários de uma empresa de tecnologia também situada em São Francisco, EUA. O Youtube se tornou o mais popular site do tipo devido à possibilidade de hospedar quaisquer vídeos, com ele pessoas de todo mundo podem enviar seus vídeos digitais, gravados a partir de filmadoras caseiras, webcams e até celulares para compartilhar com os outros usuários do site. Seu formato permite que os usuários coloquem seus vídeos em blogs, ou sites pessoais através de mecanismos desenvolvidos pelo site.

As pessoas podem ver vídeos sobre seus passatempos prediletos, assistir a programas de televisão, vídeos engraçados, vídeos institucionais, palestras, entrevistas, workshops, coberturas e participações em eventos, materiais caseiros, e podem até comentar em material de outros usuários.

Uma outra vantagem oferecida por este site de compartilhamento de vídeos é que o internauta pode criar seu próprio canal de vídeos, permitindo maior interatividade entre os usuários. Os canais são como uma página no Youtube, estes vão desde canais de cantores de música, como o canal do cantor Gilberto Gil para divulgação de músicas para seus fãs, e até o canal do Vaticano, com vídeos curtos sobre as atividades do Papa Bento XVI, além de eventos e cultos, com áudio e texto. As empresas podem criar seu Brand Chanel, seu próprio canal para fortalecer o relacionamento com o consumidor.

Todo o potencial do Youtube foi reconhecido pela revista americana Time, que elegeu o site como a melhor invenção de 2006, entre outros motivos, por "criar uma nova forma para milhões de pessoas se entreterem, se educarem e se chocarem de uma maneira como nunca foi vista". (G1, 2006)

O grande sucesso deste site de partilha de vídeos despertou o interesse da empresa Google Inc., interessada em expandir o mercado de publicidade de vídeos e em se consolidar como um dos maiores serviços de internet do mundo. A compra do Youtube pela Google foi anunciada em 9 de outubro de 2006 pela quantia de US\$1,65 bilhão em ações.

\section{MARKETING NO YOUTUBE}

O Youtube é uma das ferramentas de busca mais usada depois do Google, muita gente hoje pesquisa por palavras (e imagens) em movimento e não só por textos. Com isso, as empresas estão descobrindo que é cada vez mais importante se comunicar através de imagens com o mercado.

0 uso do Youtube como ferramenta de marketing possibilita as empresas a disponibilizarem seus vídeos comerciais tendo duas principais vantagens: o custo e a possibilidade de que se as pessoas gostam do vídeo, elas podem espalhar o seu conteúdo e até mesmo disponibilizarem 
em seus sites pessoais sem dificuldades.

Muitas grandes empresas já estão compartilhando vídeos com usuários da rede. Isso demonstra o quanto elas estão levando a sério a imagem social da empresa na Internet. Saber explorar essa oportunidade é um diferencial enorme para marcar presença na web.

Criar um canal no Youtube pode trazer vantagens para a empresa, pois pode usar este espaço para divulgação de lançamento de produtos, novidades da empresa, etc. As marcas rapidamente introduziram o canal nas suas ferramentas de trabalho, podendo transformá-lo em um canal de comunicação através do qual se pode fazer publicidade, mais ou menos explicita, mas sempre com um baixo custo e com um elevado nível de hits.

0 Youtube ainda disponibiliza uma ferramenta para monitorar as estatísticas de acesso dos vídeos, para saber quem assiste, quando o assiste e como o usuário chegou até o vídeo. Esta ferramenta gratuita chamada Youtube Insight é útil tanto para satisfazer a curiosidade de quem posta o vídeo para se divertir quanto para quem posta um vídeo com fins promocionais.

Com o uso do Youtube, as empresas têm a chance de produzir e distribuir vídeos digitais de seus produtos/serviços de forma fácil, rápida e econômica, dispensando assim aquela apresentação no PowerPoint para levar para o seu cliente. Possibilita a produção de um vídeo mais moderno, personalizado e conceitual, para enviar o link para o cliente, colocar em seu site, e ainda deixará a disposição de milhões de pessoas na internet.

Além disso, é uma importante ferramenta de marketing em função de sua capacidade de multiplicação do vídeo, e da ferramenta de busca que incorpora, que permite ao Internauta, literalmente, descobrir seu vídeo. E ainda exibe filmes associados ao tema de forma arbitrária e em playlist.

Na reportagem "Empresas procuram espaço para seus produtos no Youtube" do site da Universia Knowledge Wharton, um porta-voz do Youtube declarou em um email:

A plataforma de marketing viabilizada pelo site está cem por cento associada à participação do público. Nossos usuários fazem festa para os anúncios que consideram de boa qualidade e se sentem motivados a expressar sua opinião sobre os anúncios de que não gostam. Eles compartilham anúncios e fazem comentários sobre eles, reagem à publicidade propondo um conteúdo produzido por eles mesmos, participando de concursos e de diálogos criativos com outros que compartilham com eles os mesmos interesses. É essa participação ativa que muitos anunciantes desejam, para que possam se comunicar com novos clientes e atingi-los. ${ }^{1}$

\section{IMOBILIÁRIAS NO YOUTUBE}

O Youtube responde por cerca de um terço de todos os vídeos vistos pela Internet, o site de propriedade da Google tornou-se muito cobiçado pelos anunciantes e caiu no gosto do segmento imobiliário. Diversas imobiliárias e construtoras estão usando o serviço de postagem gratuita do portal para divulgar casas e apartamentos para locação ou venda através da rede mundial de computadores.

${ }^{1}$ Disponível em:

<http://www.wharton.universia.net/index.cfm?fa=viewArticle\&id=1502\&language=portuguese\&specialId $>$ 
Devido à grande concorrência do mercado imobiliário, se faz necessário que as empresas do ramo busquem um diferencial, pois todas usam praticamente os mesmos meios de divulgação, formas de informação e comunicação com os mesmos argumentos para atrair seus clientes potenciais. Além de diferenciais que destaquem a empresa da grande concorrência, deve-se ter também estratégias que sejam eficazes para os negócios de venda e/ou aluguel dos imóveis. Por isso é crescente o movimento de imobiliárias que utilizam o Youtube como ferramenta para divulgar vídeos para exibir seus empreendimentos.

A Google fez uma pesquisa sobre o comportamento do consumidor na aquisição de um imóvel, e segundo esta, $88 \%$ das pessoas com acesso à internet fazem uso deste meio para a procura de imóveis. As pessoas usam a internet principalmente para localizar imóveis à venda

que mais se enquadrem com suas necessidades, corretores, imobiliárias, montar planejamento/orçamento de compra, pesquisa de bairros/vizinhança e valor de compra. Isso reforça a atenção que o segmento imobiliário deve ter com esta mídia, pois assim, pesquisando por conta própria, podem usar o tempo do corretor de maneira mais eficiente e produtiva. $^{2}$

A pesquisa sobre o mercado de imóveis brasileiro da Google ainda demonstra que $72 \%$ dos compradores afirmam que anúncios online têm impacto positivo na sua motivação de compra, sendo anúncios em vídeo e banners animados considerados mais influentes por $75 \%$ dos que responderam.

0 uso de um vídeo pode ser uma estratégia inteligente relacionada à falta de tempo das pessoas. Elas têm a opção de fazer uma lista dos imóveis que lhes interessa ver e economizar o tempo que perderiam indo visitar todos aqueles oferecidos pelo corretor. Segundo as imobiliárias que já usam o sistema, o registro em vídeo é mais eficaz que as fotos, uma vez que permite ao consumidor ter uma noção melhor do espaço e da distribuição dos cômodos. Assim, os vídeos postados no Youtube podem ser disponibilizados nos próprios websites das corretoras para divulgação.

Os internautas podem encontrar desde vídeos profissionais, em que as imobiliárias contratam serviços para divulgação no site, até produções caseiras de baixa resolução, tem "construtoras que transformam as imagens de plantas em vídeos, pessoas que passam em frente à câmera atrapalhando a filmagem e até imobiliárias que apostam em músicas de fundo para "envolver" possíveis compradores". (G1, 2006).

Além disso, é uma forma de se aproximar do consumidor e também melhorar sua estratégia de comunicação. Além de contribuir para a opção de venda, essa ferramenta pode funcionar como um novo instrumento para captar clientes, divulgar seus imóveis e acelerar negócios pela Internet.

\section{ESTUDO DE CASO DA CONSTRUTORA DE IMÓVEIS TECNISA}

A Tecnisa começou sua história em 24 de setembro de 1977, fundada pelo estudante de engenharia civil da Politécnica da USP, Meyer Joseph Nigri. Nominada inicialmente por Tecnisa Engenharia, foi criada com a missão de se transformar em uma grande construtora e incorporadora no segmento da construção residencial brasileira. Seu primeiro empreendimento residencial, o edifício chamado Porto Vecchio, foi entregue em 1981.

Situada na cidade de São Paulo, sua especialidade são os empreendimentos residenciais, 
porém trabalha também com escritórios, flats e condomínios de casas.

2 Dados baseados em pesquisa Media-Screen de Julho de 2008, com 605 pessoas no Brasil que compraram ou estavam pesquisando imóveis residenciais para compra nos últimos 6 meses.

Na década de 90, a Tecnisa criou o conceito de roof top, no qual procurava se diferenciar da maioria dos empreendimentos construindo edifícios com o lazer na área da cobertura e não no térreo, como os demais. Pregava também o grand space, em que empreendimentos compactos eram construídos nas regiões nobres de São Paulo sem acréscimo proporcional de preço.

Na década seguinte, a construtora apostou na inovação, investindo em responsabilidade social, desenvolvendo suas áreas de marketing, relacionamento com o cliente e internet.

A Tecnisa lançou diversos projetos na área de responsabilidades social relacionados com o seu negócio, que fizeram com que a empresa ganhasse prêmios como o Prêmio Amanco por um Mundo Melhor em 2003 e 2004, o mais importante do segmento; e o Master Imobiliário de Responsabilidade Social em 2004. Seu foco é a alfabetização adulta e a capacitação técnica. Seus projetos são:

- Alfabetização digital: esse projeto tem o objetivo de inclusão digital dos operários, no qual a empresa promove cursos de capacitação na área de informática, dados por funcionários voluntários, para os operários.

- Ler e Construir: consiste em um programa de alfabetização de adultos com aprimoramento cultural e social dos seus funcionários, em salas instaladas nos canteiros das obras.

- Primeiro Emprego: objetiva dar oportunidades para jovens com idade superior a 18 anos ingressarem formalmente no mercado de trabalho.

- Profissionais do Futuro: para melhorar o processo de contratação de operários qualificados, a Tecnisa criou cursos de capacitação adulta.

- Projeto Vizinho: para melhorar o convívio com as pessoas que moram próximas às áreas de obras da Tecnisa, a empresa criou um canal de comunicação para sugestões, reclamações e acordos, por meio do e-mail vizinho@tecnisa.com.br.

- Função Gol de Letra: uma parceria com a entidade criada por ex-jogadores da seleção brasileira Raí e Leonardo com o objetivo de contribuir com a melhoria da qualidade de vida das crianças brasileiras menos favorecidas, através de uma série de projetos de assistência à infância com educação e esportes.

- Projeto Felicidade: criado pela instituição judaica Beit Chabad do Brasil, em 2001, tem como objetivo proporcionar diversão e alegria às crianças carentes portadoras de câncer.

Com seu slogan "Mais construtora por $\mathrm{m}^{2 ”}$, a Tecnisa desenvolveu competências específicas 
para criar um relacionamento diferenciado com seus clientes. 0 trabalho de relacionamento com o cliente começou em 2002, em 2003 os resultados demonstravam que 11\% das vendas foram realizadas por indicações e, em 2004, 18\%.

Em 2004 a empresa começou aconcorrer e conquistar o Prêmio Consumidor Moderno de Excelência em Serviços ao Cliente, no segmento de construção civil. De lá para cá esse passou a ser um dos objetivos do Departamento de Relacionamento com o Cliente da Tecnisa. Em 2006 e 2007, essa conquista se tornou 40\% da meta anual da equipe, com bônus por isso.

Para um bom relacionamento com o cliente, a empresa adota estratégias como o envio de vários objetos simbólicos, adequados a cada fase do empreendimento, para os clientes em caixas acompanhadas de cartas personalizadas. Além disso, são enviados mensalmente mensagens por emails informando o cronograma da obra, com fotos e áudio personalizado. Inclusive, podem-se

obter também através do link enviado por email, informações sobre a formação profissional do engenheiro responsável. 0 objetivo é fazer com que, ao ouvir seu nome quando receber a mensagem em áudio, o cliente esteja ciente do empenho em atendê-lo de forma cuidadosa e detalhada, mostrando que este é especial em todas as fases do projeto, desde a assinatura do contrato até a entrega das chaves.

A Tecnisa abriu seu capital em fevereiro de 2007, assim, teve que intensificar suas práticas de transparência junto a um novo stakeholder, o investidor. 0 mercado de capitais não é opção para qualquer empresa, a começar pelo custo de abertura do capital, que não é barato. A empresa precisa ter boa governança corporativa e obter lucros para distribuir dividendos aos acionistas. Do contrário, o preço das ações despencará e ela não deverá conseguir captar novos recursos.

Uma das ferramentas de relacionamento com seus investidores é o seu site, que contém relatórios anuais com informações de Governança Corporativa, estratégia e metas da organização, desempenho econômico-financeiro, recursos humanos, relacionamentos, sustentabilidades, perspectivas, premiações e informações corporativas.

Com a abertura do capital em 2007, a empresa conseguiu captar cerca de meio milhão de reais nesse ano para pagamento de dívidas de curto prazo e aplicações em compras de terrenos e aquisição de projetos de outras empresas. E ainda apostou na mudança de foco da companhia, que historicamente concentrou-se em projetos nas classes alta e média alta e passou a aumentar sua participação na classe média e ingressar no segmento popular.

Figura 1: Logotipo da Tecnisa

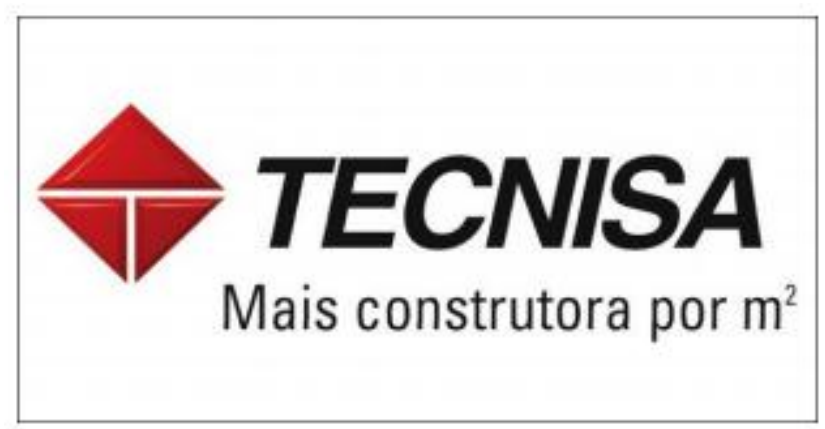

Fonte: <http://www.tecnisa.com.br/> 


\section{A TECNISA NA INTERNET}

A Tecnisa foi uma das empresas pioneiras no Brasil do mercado imobiliário a investir afundo na internet, procurando utilizar os meios digitais para divulgar sua marca, atrair e manter seus clientes, e também lucrar com isso. A empresa investe nesses projetos com a intenção de atender seus clientes onde quer que eles estejam. Até aqueles mais conservadores, que preferem visitar os imóveis pessoalmente podem acompanhar ou se informar de alguns imóveis pelo site.

O Blog Tecnisa é o primeiro blog corporativo do Mercado Imobiliário. Ele foi feito pela construtora objetivando a transparência empresarial, é um meio de comunicação erelacionamento com seus stakeholders, uma forma de expor a relevância da marca e sua exposição, sempre com foco nos assuntos de construção civil e processos de compras de imóveis.

O blog também é funciona como um canal de comunicação com seus clientes de maneira que estes podem expor suas dúvidas, idéias, sugestões, críticas e frustrações. Com o sucesso do Blog,a empresa decidiu investir em outras áreas da web, como podcasting, twitter, o second life , o YouTube, entre outros.

Figura 2: Blog Corporativo da Tecnisa

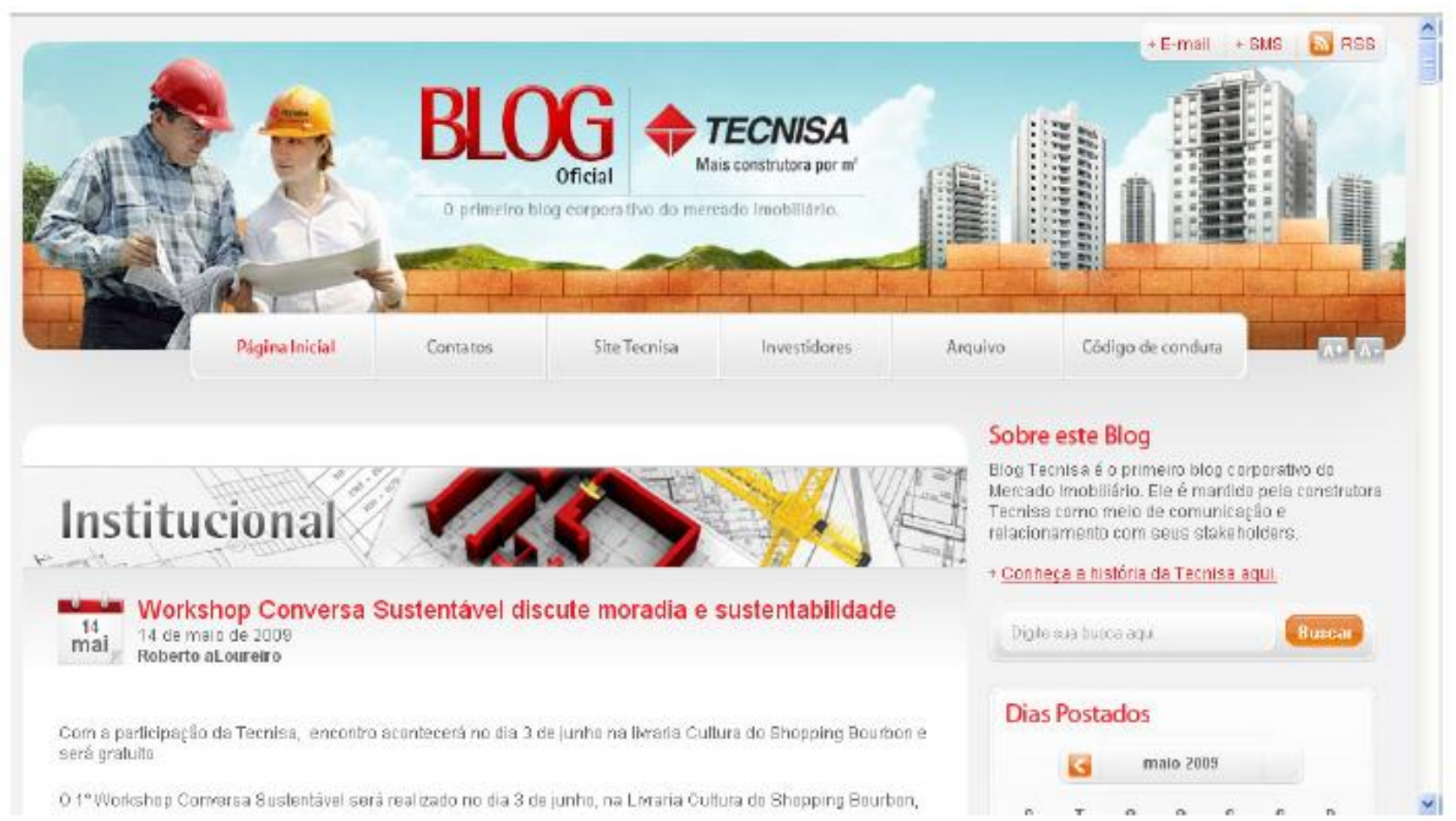

Fonte: <http://www.blogtecnisa.com.br/> Acesso em: 15 de maio de 2009

Os podcasts (combinação das palavras iPod - aparelho que toca arquivos digitais em MP3 com broadcasting, transmissão de rádio ou TV) são arquivos de áudio transmitidos via internet. 0 objetivo da Tecnisa em usar essa ferramenta é ter um canal de comunicação com seus clientes através de uma mídia em áudio, para oferecer aos internautas um conteúdo de utilidade pública relacionado com compra e venda de imóveis, entre outros assuntos que 
abrangem este mercado.

O Twitter é uma rede de relacionamento criada em 2007 que está crescendo no Brasil, é uma espécie de "microblogs" que permite a um usuário publicar mensagens curtas (de até 140 caracteres) e formar uma rede de seguidores. A Tecnisa também criou o seu como uma ferramenta de marketing, para divulgação de lançamentos dos seus empreendimentos e novidades. "A idéia é que o twitter seja mais uma ferramenta que estimule as visitas ao site, já que é possível incluir links nas mensagens, remetendo para o flick ou youtube, também usados pela Tecnisa", ressalta o diretor de marketing da Tecnisa, Romeo Busarello.

O Second Life é um ambiente virtual que simula, em alguns aspectos, a vida real e social do ser humano. A construtora é a primeira companhia do setor imobiliário brasileiro a interagir nesse programa. Em 2007 a Tecnisa começou a comercializar apartamentos verdadeiros nesse mundo virtual. A estratégia da empresa foi lançar apartamentos em réplicas virtuais idênticas às do estande real, para que o usuário pudesse visitar o estande e até mesmo comprá-lo pelo próprio Second Life, no qual um corretor on line estaria disponível em um determinado horário.

Figura 3: Alguns Canais Tecnisa

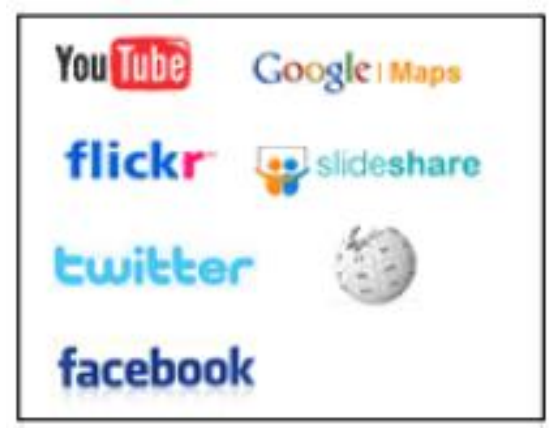

Fonte: <http://www.tecnisa.com.br/> Acesso em: 15 de maio de 2009

Além disso, dentro do próprio site da construtora, foi criada uma área para divulgação de trabalhos acadêmicos, cases e artigos. Para a empresa, essa é uma maneira de baixo custo para expor sua marca e ressaltar seu modelo de gestão, gerando vantagens como aumento da divulgação de idéias, visibilidade da marca, crescimento do network no meio academio, e contato direto com o público.

A empresa investe tanto nas redes sociais como forma de divulgação e estratégia de marketing, que criou uma nova função no organograma da área de Marketing: o Gerente de Redes Sociais. A principal atribuição desse profissional é explorar o mundo digital a procura de novas oportunidades de negócios na web, cuidar do posicionamento institucional da empresa nas redes sociais e administrar o blog corporativo.

\section{A TECNISA NO YOUTUBE}

Como uma empresa que aposta na grande visibilidade gerada pela mídia digital, não poderia ficar de fora de um dos maiores sites de compartilhamento de vídeos da internet. Assim, em outubro de 2006 a empresa começou a atuar no Youtube. 
Figura 4: Canal da Tecnisa no Youtube

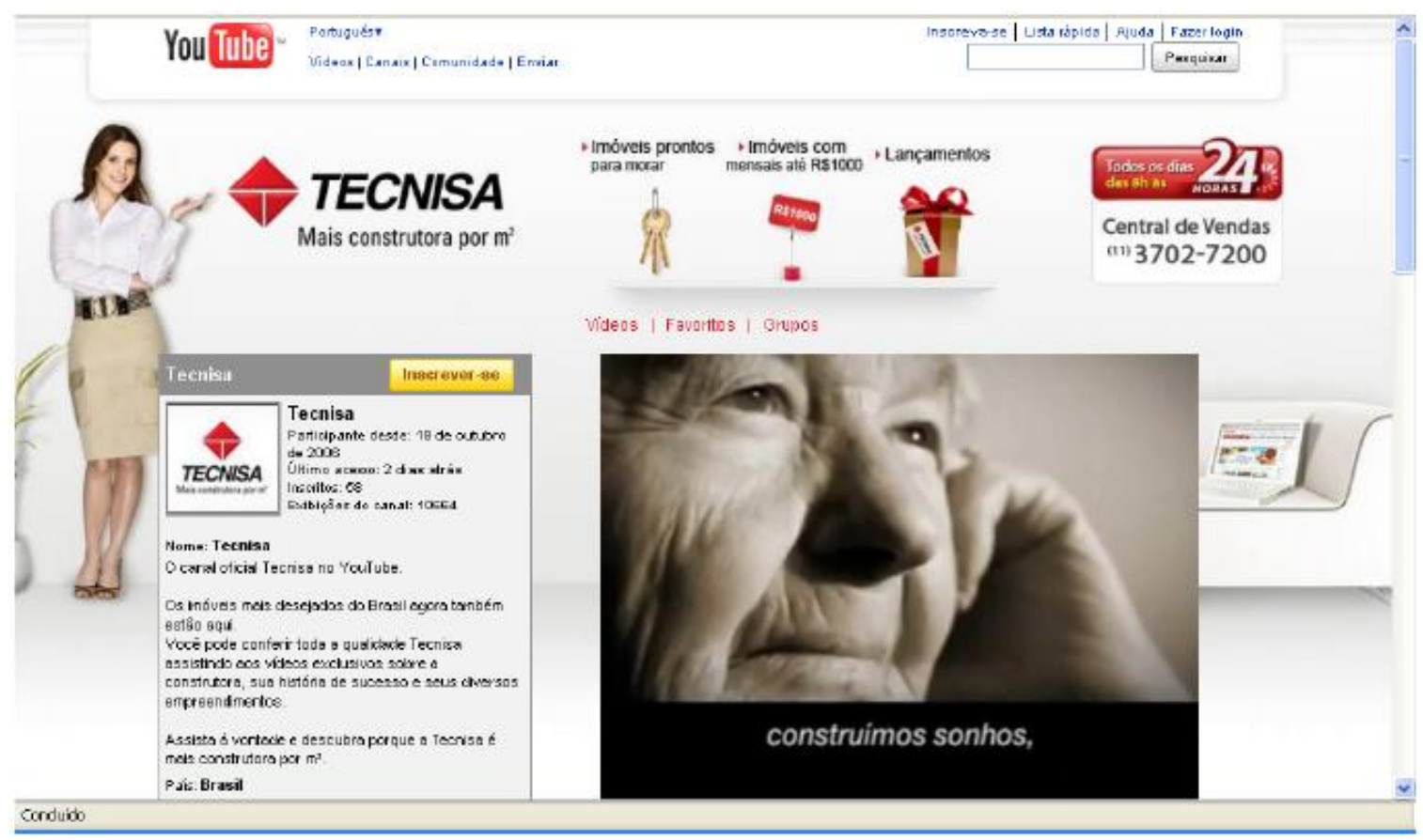

Fonte: <http://www.youtube.com/tecnisa?gl=BR\&hl=pt> Acesso em: 17 de maio de 2009

A empresa considera o Youtube com uma forma moderna de interação com seus clientes e um forte aliado ao marketing de guerrilha. No canal da Tecnisa no Youtube, a construtora disponibiliza diversos vídeos institucionais, com temas variados, como os trabalhos sociais desenvolvidos pela empresa, entrevistas com executivos, projetos diferenciados, lançamento de seus novos empreendimentos, e etc. 
Figura 5: Vídeos da Tecnisa no Canal do Youtube

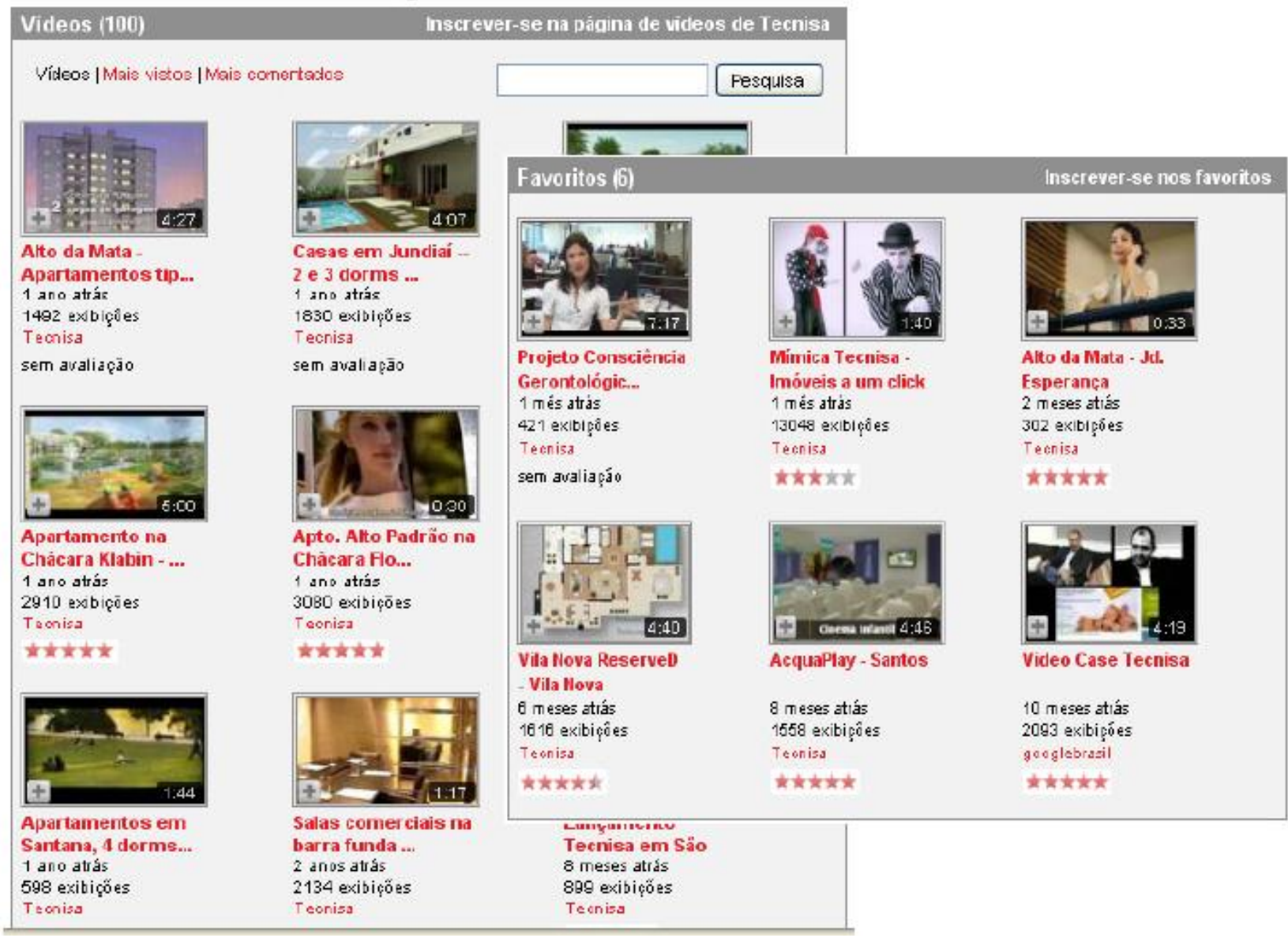

Fonte: <http://www.youtube.com/tecnisa> Acesso em: 17 de Maio de 2009

A construtora não segue uma regra para postagem dos seus vídeos, a cada lançamento de um imóvel, tenta publicar um novo vídeo. E não há vídeos apenas voltados especificamente aos clientes. Há vídeos de treinamento para os corretores, que ajudam na coleta de informações para todos os usuários.

Para obter mais informações a respeito da participação da Tecnisa no site de compartilhamento de vídeos, foi enviado para a empresa um questionário com algumas perguntas relevantes ao tema.

Considerando que uma das principais estratégias de marketing da empresa está na inserção de sua marca nas redes sociais, a primeira questão perguntava quais as principais vantagens para a Tecnisa em disponibilizar um canal com vídeos institucionais no Youtube. Segundo Denilson Novelli, Gerente de E-business da Tecnisa, uma grande vantagem está relacionada à "encontrabilidade" - termo adotado por Conrado Adolpho Vaz, autor do livro Google Marketing - pois a empresa defende a necessidade de estar sempre presente no âmbito de 
seus stakeholders, sejam eles clientes, prospects, investidores, jornalistas, estudantes, etc.

Segundo ele, quase $20 \%$ da audiência do site vem do acesso direto (recall de marca) e da busca

orgânica (clique no resultado natural dos buscadores, os não pagos). Aponta também a vantagem relacionada ao fato do Youtube ser, depois do Google, o maior mecanismo de busca utilizado no mundo, estando à frente até do Yahoo. E ainda tem o benefício do custo, pois a disponibilização de vídeos e os acessos são gratuitos, ou seja, a empresa ainda tem uma economia com investimentos em servidores.

De acordo com Novelli, desde o início de 2009, o canal de vendas pela internet supera a marca de $30 \%$ do faturamento da Tecnisa. Acrescenta ainda que "um cuidado interessante com os usuários do site da Tecnisa, que em sua maioria não são heavy users (usuários intensos) em internet, é que o player do Youtube já é bem conhecido e diminui ou até elimina a curva de aprendizado do usuário em nosso site para assistir a um vídeo."

A segunda pergunta indagava se clientes da imobiliária já haviam mencionado ter acessado ao site de vídeos antes da compra de um empreendimento e se o interesse pelo imóvel pode ter surgido após o acesso ao seu respectivo vídeo. Novelli então ressalta a importância da pesquisa antes da decisão de compra de um imóvel, uma vez que é uma decisão importante e complexa, pois se trata de um bem caro que envolve decisões de caráter emocional e racional, então é necessária a obtenção de informações detalhadas. Quando um imóvel possui um vídeo, este recurso passa a ser o quarto mais consultado, após a planta, preço e o mapa de localização, pois pode auxiliar em uma pesquisa mais aprofundada à medida que dispõe de conteúdos como imagens do modelo decorado ou descrição do imóvel, entre outras informações. Segundo o gerente de E-business da empresa, 94\% dos clientes que efetivaram a compra de um imóvel passaram antes pelo site para obter informações sobre ele.

A terceira pergunta fazia referência à faixa etária dos clientes da empresa, e considerando um site muito acessado por jovens como o Youtube em que 55\% de seus usuários possuem até 24 anos, se poderia ser considerado uma estratégia da empresa para esse público. ${ }^{3}$ A resposta obtida foi que a faixa etária dos clientes está entre 27 e 37 anos. Para a empresa, uma presença no Youtube, junto com demais sites de redes sociais, aproxima sim a marca do público mais jovem.

A terceira pergunta fazia referência à faixa etária dos clientes da empresa, e considerando um site muito acessado por jovens como o Youtube em que 55\% de seus usuários possuem até 24 anos, se poderia ser considerado uma estratégia da empresa para esse público.3 A resposta obtida foi que a faixa etária dos clientes está entre 27 e 37 anos. Para a empresa, uma presença no Youtube, junto com demais sites de redes sociais, aproxima sim a marca do público mais jovem.

E considerando que a audiência do Youtube já atinge 10 milhões de usuários por mês, então também tem uma boa cobertura na faixa principal de seu público alvo.

Quando perguntado na quarta questão se a empresa presta algum acompanhamento para os acessos dos vídeos assistidos, a resposta foi que a empresa mensura toda navegação no site e monitora o tempo de acesso e visualização de seus vídeos. E ainda utiliza o Google Analytics, uma ferramenta gratuita da Google para analisar as estatísticas de visitação do seu site, para análise do comportamento no site da Tecnisa. Essa ferramenta também já está disponível no Youtube para alguns parceiros, que permite o acesso a métricas como número de vezes que 
cada utilizador acede a determinadas páginas, o tempo que os usuários passam em cada página assim como informação geográfica e idioma utilizado.

A quinta pergunta questionava a Empresa sobre o fato de que os vídeos além de dar uma noção melhor sobre os imóveis, se também passavam maior credibilidade para os clientes potenciais. A resposta obtida foi que a empresa preza muito pelo conteúdo em seu site, para que o usuário possa tirar todas as dúvidas possíveis sobre o imóvel e auxiliá-lo na decisão de compra. Inclusive, o internauta pode ser atendido por um corretor online com plantão de $24 \mathrm{~h}$, e um vídeo é usado como um grande reforço nesta estratégia.

${ }^{3}$ Fonte: http://www.slideshare.net/dttg/media-kit-youtube-brasil-presentation

A sexta pergunta indagava a empresa sobre seus planos de explorar mais o Youtube. De acordo com o gerente Denilson Novelli, no início de 2009 foi feita a página personalizada (brand channel) da Tecnisa e iniciou-se campanhas com palavras patrocinadas e vídeos no portal, que se intensificarão durante os próximos meses.

A sétima e última pergunta mencionava se a empresa considera o Youtube como uma ferramenta eficaz para a promoção dos empreendimentos e da marca. E ela afirmou que sim, pois já conta com mais de 160 mil visualizações em seus mais de 100 vídeos no Youtube. E seu brand chanel já foi visualizado mais de 11 mil vezes, um número excepcional para a construtora que ajuda a construir a marca da empresa.

\section{CONCLUSÃO}

Com a importância das tecnologias como meio de divulgação de produtos de uma empresa, é de suma necessidade que as empresas utilizem estratégias para campanhas publicitárias online. A Tecnisa teve essa percepção e está marcando presença na internet. Está inserida em sua estratégia de marketing a inserção no mundo digital, fazendo com que sua marca seja visualizada em diferentes áreas da web.

A Construtora aposta em novas formas de relacionamento com o internauta para gerar negócios. Desde que lançou seu site focado em e-commerce, a construtora vem comemorando o impacto positivo da presença on-line nos resultados de vendas. A postura de vanguarda da Tecnisa em relação às potencialidades da internet faz a empresa ser bastante pró-ativa e, ao mesmo tempo, ousada no relacionamento com os internautas.

A estratégia da Tecnisa no Youtube é principalmente o fomento e disseminação da marca, e a disponibilização dos vídeos de seus imóveis colabora com as vendas de maneira a divulgar informações sobre os empreendimentos e auxiliar o cliente em potencial em suas pesquisas para a decisão de compra. A coleta de informações é indispensável, e a prova de que o site é de grande importância é o fato de que muitos clientes já mencionaram na compra do imóvel terem colhido informações no Youtube para suas pesquisas antes da compra.

Portanto, conclui-se que o Youtube é uma interessante forma de propaganda e pode ser muito bem explorado pelas empresas, e principalmente pelas imobiliárias, conforme o estudo apresentado. Em um cenário atual em que as pessoas fazem procura por imóveis até durante a madrugada pela internet e considerando que atualmente a este é o veículo mais usado como apoio a decisão antes da compra de um imóvel, o uso do Youtube pelas imobiliárias é de 
extrema importância e pode ser um dos fatores decisivos para concluir vendas.

\section{REFERÊNCIAS BIBLIOGRÁFICAS}

BLESSA, Regina. Merchandising no ponto-de-venda. São Paulo: Atlas; 2001.

BLOG Marketing Imobiliário \& Estratégias Corporativas. Google, a História do Google.

Disponível em: <http://www.inaciorodrigodecastro.com.br/google-historia-do-google> Acesso em 10 de maio de 2009.

BLOG OFICIAL TECNISA. Disponível em: < http://www.blogtecnisa.com.br/>. Acesso em 15 de maio de 2009.

CHURCHILL, Gilbert A. Jr.; PETER, J. PAUL. Marketing: criando valor para os clientes. São Paulo: Saraiva, 2000, 2a edição.

COBRA, Marcos. Marketing Básico. São Paulo: Atlas, 1997

COBRA, Marcos. Marketing de Serviço Financeiro. São Paulo: Cobra, 2000.

DARROCH, J. et al. The 2004 AMA definition of marketing and its relationship to a market orientation: an extension of Cooke, Rayburn, \& Abercrombier (1992). The Journal of Marketing - Theory and Practice, v.12, n.4, p. 29-38, fall 2004.

DIZARD, Wilson. A nova mídia. Rio de Janeiro: Zahar, 2000. G1. Conheça a história do site de vídeos YouTube. 2006. Disponível em: <http:// g1.globo.com/Noticias/Tecnologia/0,AA1306288-6174,00.html>. Acesso em 08 de maio de 2009.

G1. Empresas usam Youtube para divulgar imóveis à venda. 2006. Disponível em: <http://g1.globo.com/Noticias/Tecnologia/0,AA1350522-6174,00.html>. Acesso em 10 de maio de 2009.

GILLMOR, Dan. Nós, Os Media. Lisboa: Editorial Presença, 2005.

KOTLER, Philip.; ARMSTRONG, Gary. Princípios de marketing. 9. ed. São Paulo: Prentice Hall, 2003.

KOTLER, Philip e KELLER, Kevin. Administração de Marketing - 12a Edição. São Paulo: Prentice Hall, 2006.

KOTLER, Philip. Marketing de A a Z: 80 conceitos que todo profissional precisa saber. 2. ed. Rio de Janeiro: Campus, 2003.

KOTLER, Philip. Administração de Marketing: a edição do novo milênio. São Paulo: Prentice Hall, 2000.

LAMB, Charles W. Princípios de Marketing. São Paulo: Pioneira Thomson Learning, 2001.

LAS CASAS, Alexandre L. Marketing: conceitos, exercícios, casos. 4a Edição. São Paulo: Editora Atlas, 1997. 
MCCARTHY, Jerome E. \& PERREAULT, W. D. Marketing Essencial. São Paulo: Atlas, 1997. MIDDLETON, V.T.C. Marketing de Turismo: teoria e prática. Rio de Janeiro: Elsevier, 2002. NICKELS, William G; WOOD, Marian Burk. Marketing: Relacionamentos, Qualidade, Valor. Rio de Janeiro: LTC, 1999.

ROSA, César Augusto Salabert. Internet: história, conceitos e serviços. São Paulo: Érica, 1998.

SANT'ANNA, Armando. Propaganda: Teoria, técnica e prática - 7̣a edição; São Paulo: Atlas; 1998.

SCHEWE, Charles D.; SMITH, Reuben M. Marketing: Conceitos, Casos e Aplicações. Editora McGraw - Hill do Brasil. São Paulo, 1982.

SLIDESHARE. Media Kit Youtube Brasil. Disponível em: <http://www.slideshare.net/dttg/media-kit-youtube-brasil-presentation>. Acesso em $20 \mathrm{de}$ maio de 2009.

TECNISA. Apresentação e História. Disponível em: <http://www.tecnisa.com.br/institucionalhistoria. html>. Acesso em 16 de maio de 2009.

UNIVERSIA KNOWLEDGE WHARTON. Empresas procuram espaço para seus produtos no Youtube. Disponível em: <http://www.wharton.universia.net/index.cfm?fa=view Article\&id=1502\&languageportuguese\&specialId.> Acesso em 11 de maio de 2009.

VASSOS, Tom. Marketing Estratégico na Internet. São Paulo: Makron Books do Brasil, 1998.

VERGARA, S. C. Projetos e Relatórios de Pesquisa em Administração. São Paulo: Atlas, 2001.

YOUTUBE. Canal da Tecnisa. Disponível em: <http://www.youtube.com/tecnisa>. Acesso em 05 de maio de 2009. 